\title{
The use of public records acts to interfere with tobacco control
}

\author{
Stella Aguinaga, Stanton A Glantz
}

\begin{abstract}
Objective-To examine the content of public records requests to the tobacco control section (TCS) of the California Department of Health Services (CDHS) and other health agencies to determine if the tobacco industry is using the law to interfere with tobacco control.

Methods-Data were collected through review of TCS files, newspapers, Californians for Smokers' Rights publications, and interviews with key informants. Requests sent to the CDHS AIDS and Drug and Alcohol Program, the Department of Education HIV Prevention Program, and the Air Resources Board (ARB) were used as controls. Results-Between 1991 and 1993, TCS received 59 requests for 371 documents, averaging 15.5 documents per month. Control health programmes did not receive any document requests during this period. ARB received their usual requests for approximately 100 narrowly specified documents a year.

Conclusions-Tobacco control programmes received a high volume of public records requests compared to other health programmes. The information obtained was used for public relations efforts to discredit tobacco control programmes. Public health professionals must be aware of this tobacco industry tactic to undermine public health. Departmental policies addressing response to public records requests must consider ways to respond to large requests without disruption of the work of public health professionals.
\end{abstract}

(Tobacco Control 1995; 4: 222-230)

Keywords: tobacco control; health policy; health education; public records

Institute of Health

Policy Studies,

Department of

Medicine, University

of California at San

Francisco, San

Francisco, California

94143, USA

$S$ Aguinaga

SA Glantz

Correspondence to: $\mathrm{Dr}$ Stanton A Glantz, Division of Cardiology, University of California at San Francisco, San Francisco, CA

94143-0124, USA

Abbreviations used

ARB Air Resources Board

\section{Introduction}

The federal Freedom of Information Act (FOIA) enacted in 1966 requires that federal agencies make their records promptly available upon request to any person, without regard to the reasons for the request. It has nine exemptions, mainly to protect national security, trade secrets, and privacy. ${ }^{1}$ It was amended in 1974 and 1976 to narrow the scope of the exemptions. The FOIA was passed during a time of great public concern about government secrecy regarding the Vietnam War, was amended following the Watergate scandal, and was intended to allow American citizens to monitor their government's activities. ${ }^{2}$ In 1968, California, like many other states, created the California Public Records Act (CPRA), modelled after the federal Freedom of Information Act. ${ }^{3,4}$ The CPRA "is designed to give public access to information in possession of public agencies," 3 and is used by the public and the press to inspect public documents and monitor public expenditures. The public policy goal of these laws was to provide citizen access to information collected by the government, thereby ensuring an open governmental process. The tobacco industry, however, has been using freedom of information laws not simply to collect information, but as another tactic in its strategy to interfere with activities of public health agencies seeking to reduce tobacco use.

We studied the requests for documents under the CPRA to determine if the tobacco industry's use of the freedom of information act is different from requests made by the public and other businesses and interest groups. The tobacco industry's use of freedom of information laws as a tactic against public health efforts raises management and policy issues for government agencies that have an obligation to promote public health by reducing tobacco use and that respond to
ASSIST

CDC

COMMIT

COMM

CSR

FOIA

LLA

NCI

OSH

TAPS

TCP

UCSD

American Stop Smoking Intervention Study for Cancer Prevention

Centers for Disease Control and Preventio

California Department of Health Services

Community Intervention Trial for Smoking Cessation

California Public Records Act

Californians for Smokers' Rights

Freedom of Information Act

Local Lead Agency

National Cancer Institute

Office on Smoking and Health

Teenage Attitudes and Practices Survey

Tobacco Control Project

Tobacco Control Section

University of California at San Diego 


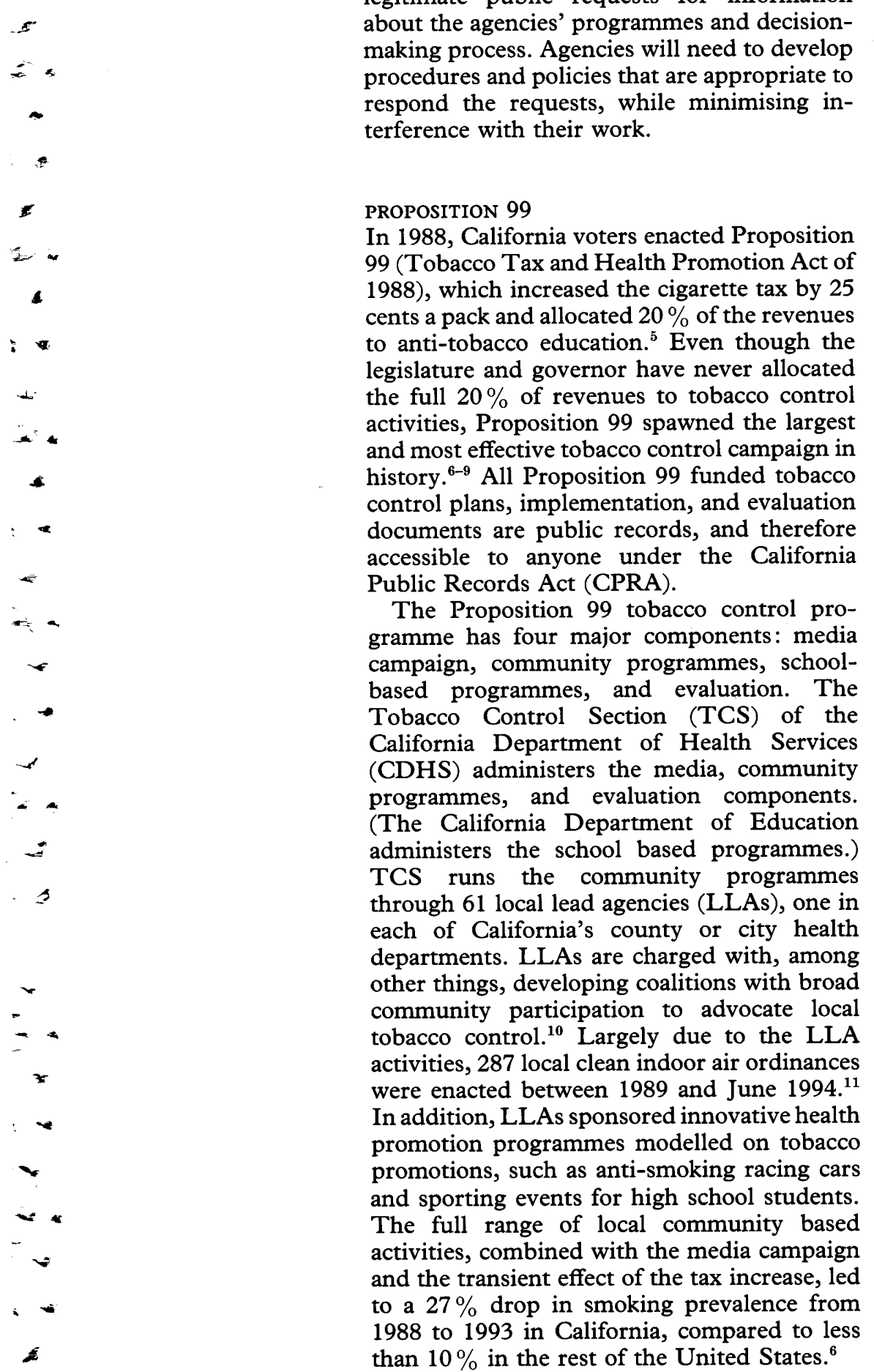

Methods

Our primary emphasis is studying CPRA requests directed at state and local health departments in California charged with implementing Proposition 99's tobacco control programme. Data collection was conducted from November 1993 through June 1994. Data were collected through examination of TCS CPRA files, which were organised by date, requester, and destination, as well as open ended structured interviews with staff from TCS, LLAs, the American Lung Association, and the American Heart Association. Interviews were recorded and followed a general outline. We interviewed individuals directly involved in responding to the CPRA based requests as well as those involved in coalitions and LLAs with activities on which the CPRA requests were focused. For comparison with other tobacco control programmes, we also interviewed staff from the National Cancer Institute (NCI) community intervention trial for smoking cessation (COMMIT) and American stop smoking intervention study for cancer prevention (ASSIST) and other state health departments. We selected state health departments that are part of ASSIST and that have been the target of public records request activities.

As control groups, we selected three programmes: the CDHS AIDS and Alcohol and Drugs programmes, and the Department of Education HIV Prevention Program. These programmes were selected because they are health promotion programmes addressing potentially controversial issues that may motivate the public or organised citizen interest groups to make CPRA requests. As an additional control, we used the California Air Resources Board (ARB), a regulatory agency which is part of the California Environmental Protection Agency (CalEPA). All the control programmes' funding comes from the state general fund and, in some cases, matching federal funds. They differ from the tobacco control programme in that they are not funded by a specific tax.

We also investigated possible connections between the authors of the CPRA requests and the tobacco industry through interviews, newspaper articles, and the newsletters and publications from Californians for Smokers' Rights (CSR). CSR is a non-profit corporation created in 1991 to protect the rights of Californians to smoke, and to monitor and oppose tobacco control activities at the state and local level, ${ }^{12,13}$ and is similar to other groups organised by the tobacco industry. ${ }^{14-18}$ Our task was to determine whether such requests were part of a coordinated campaign by pro-tobacco interests or just a random awakening of concerned citizens.

\section{Results}

Between January 1991 and December 1993 TCS received 59 CPRA requests for 371 documents, encompassing a broad range of documents such as LLA progress reports and quarterly cost reports, local and regional programme plans, grants, and state surveys and evaluation reports. Some requests were for several documents and some were for "all" documents related to Proposition 99. The CPRA activity, strong during April and May 1991 (17 requests), and March 1992 (four requests), intensified throughout 1993 (35 requests). Several thousand pages were copied, averaging 15.5 documents per month. TCS staff estimates that they spent at least eight hours to respond to each request. In some instances, due to the extent of the request, TCS was not able to comply immediately with the full request, and the author of the request instead accepted reports and other printed material that were already available to the 


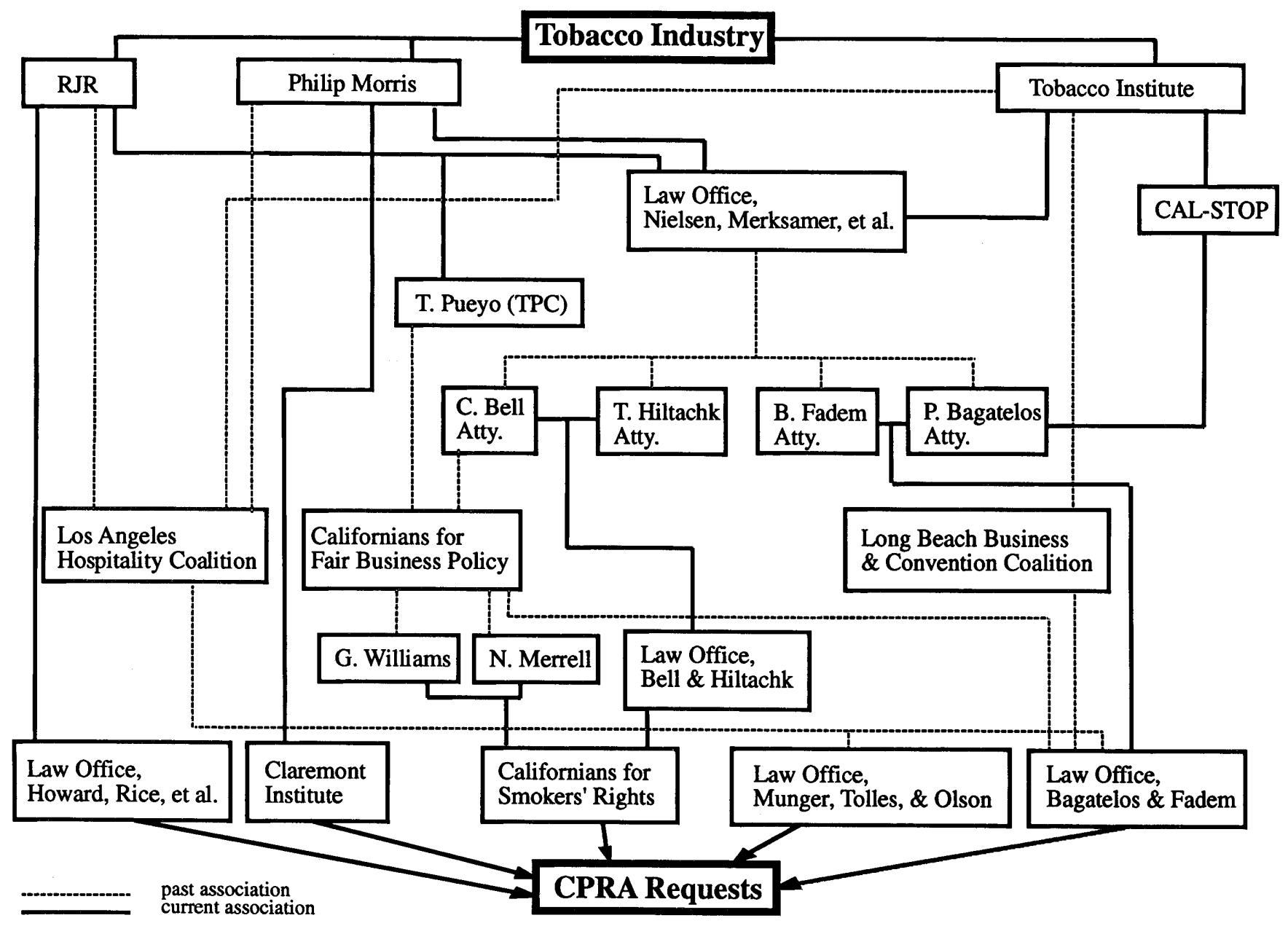

Connection between CPRA requestors and the tobacco industry.

public, such as Toward a Tobacco Free California, ${ }^{19-22}$ a series of reports on progress and plans for Proposition 99 published by CDHS.

\section{SOURCES OF CPRA REQUESTS}

During the time period studied the authors of requests changed over time with little overlap; as soon as requests from a particular firm or group ceased to arrive, requests from another source would start. The figure displays the apparent connections between most of the CPRA requestors and the tobacco industry.

In April 1991, Munger, Tolles and Olson, a law firm based in Los Angeles, made one large CPRA request, the first request received by TCS, which asked for all Proposition 99 documents. (One year earlier, this firm had requested all documents related to the research and market surveys conducted by CDHS before the development of the health education and media campaign.) Later this firm was associated with Los Angeles Hospitality Coalition, a tobacco industry front group involved in defeating local ordinances. ${ }^{8,23}$ From April to June 1991, the CPRA requests came primarily from the law firm of Nielsen, Merksamer, Hodgson, Parrinello and Mueller, through two of their lawyers, Paul Dobson and Thomas Hiltachk. This law and lobbying firm has longstanding ties with the tobacco industry and represents, among other clients, the Tobacco Institute, RJ Reynolds, and Philip Morris; and it has received over $\$ 2$ million from the tobacco industry since $1988 .^{24}$

In January 1992, when Nielsen, Merksamer, Hodgson, Parrinello and Mueller stopped filing CPRA requests, requests came from the law firm of Howard, Rice, Nemerovski, Canady, Robertson and Falk, through an attorney, H Joseph Escher III, representing RJ Reynolds ${ }^{25}$ (January to April, 1992). This firm requested the data tapes of the California Tobacco Survey, conducted by University of California at San Diego (UCSD) for TCS. (The California Tobacco Survey produced, among its findings, data showing that RJR's "Joe Camel" cartoon character led more children to smoke. ${ }^{26}$ )

In August 1992, Californians for Smokers' Rights (CSR) started its search for all of Proposition 99 documents, through its president, Bob Merrell, its employee, Glenn Williams, or its legal representative, Thomas Hiltachk, now with the law firm Bell and Hiltachk. CSR filed the most CPRA requests (58\% of the total). The connection between CSR and the tobacco industry was made explicit in a letter from a CSR member to a San Carlos City Council member which stated that "the postcard came from RJ Reynolds Tobacco Co-backed-Californians for Smokers' Rights. "27 CSR shares its mailing lists with RJ 


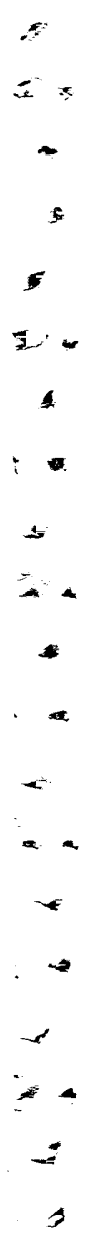

$\checkmark$

$\checkmark$

$=$

$\times$

$-$

$\checkmark$

$-$

$v$

\&

6

13

$+$

-

$E$

6

1

*

4
Reynolds and both Naylane Merrell, CSR's Secretary, and Glenn Williams, CSR's employee, worked for Sacramentans (later Californians) for Fair Business Policy, a tobacco industry front group heavily involved in opposing local ordinances (in California) in Sacramento, Long Beach, Visalia, El Dorado, Oroville, Paradise, and Sebastopol. ${ }^{15,28,29}$ Charles Bell, Thomas Hiltachk's partner, was the treasurer of Sacramentans for Fair Business Policy.

In Autumn 1993, while CSR was still active in its CPRA campaign, the Claremont Institute, a not-for-profit political science analysis group, requested all Proposition 99 related documents either directly or through a consulting firm, Nelson Consulting. The Claremont Institute received $\$ 40000$ from Philip Morris USA in $1993 .^{30}$

\section{CHARACTERISTICS AND IMPLICATIONS OF REQUESTS}

The requestors for Proposition 99 documents also attempted to intimidate TCS employees through requests for personal information (for example, salaries), and threats of immediate legal action if TCS did not comply with the request. CSR was the most aggressive of the CPRA requesters in the use of this type of strategy. Early in its campaign, CSR's lawyer, Thomas Hiltachk, contacted TCS weekly to follow up on Bob Merrell's requests, even after he was told by TCS that some of the documents requested were not yet available to the public. Most of CSR's CPRA letters stated "if I have not received a response... I will be forced to begin legal proceedings to enforce my 'fundamental and necessary right' [to] access public information." 31 This threat of legal action was constantly used, even though TCS consistently responded to the requests.

When TCS redacted the names of individual employees on Quarterly Costs Reports to protect LLA employees from invasion of privacy, CSR considered this unacceptable. CSR verbally threatened to sue TCS staff for not complying with its right to review public records. After a series of consultations between TCS and CDHS attorneys, TCS decided it could protect the privacy of their local and contract employees and withheld the information; CSR did not file their threatened lawsuit until March 1995. Glenn Williams filed for a writ of mandate against TCS at the Sacramento County superior court (Case No 95CS 00615) to have access to the names in the Quarterly Costs Report of 38 LLAs from 1991 to June 1993. At this time, the supervising deputy attorney general decided that the names were of public record, and TCS had to copy the reports for Williams without further court dispute. ${ }^{32}$ As part of the settlement, TCS was instructed to assume all costs associated with copying the reports. TCS is currently resisting efforts to force it to pay the $\$ 15000$ in Williams' attorney fees.

The requests also disrupted the work of TCS staff. A response to one of the earliest requests (April 1991) made by the law firm
Munger, Tolles and Olson stated that complying with the request for over 300 files would be "burdensome, disruptive, and time consuming," and suggested that arrangements be made for a clerk from the law firm to come to TCS with a copy machine to copy the documents. ${ }^{33}$ This approach was the only reasonable solution to comply with the request without diverting TCS staff for days or weeks. The law firm declined this offer and accepted 27 documents and reports that TCS provided that addressed all the topics included in the request.

In September 1993, Nelson Consulting, representing the Claremont Institute, requested all documents related to programmes funded by Proposition 99 money since November $1988 .{ }^{34}$ TCS estimated that to comply with such request would have required one or two staff persons for at least a month working full time. ${ }^{35}$ Nelson ultimately accepted all reports already available to the public. The firm also stated that their client would come to TCS with his own copy machine. (This had not happened as of May 1995.)

CSR did bring its own copy machine to TCS offices on several occasions. In such cases, according to CDHS policies, no fees are charged for copying or for staff time required to respond to CPRA requests. ${ }^{36}$

\section{LOCAL LEAD AGENCIES}

Local Lead Agencies (LLAs) in county and city health departments also received CPRA requests for hundreds of documents, primarily in February 1993. At least 12 LLAs (Alameda, Contra Costa, Fresno, Los Angeles, Madera, Marin, Mendoncino, Riverside, Sacramento, San Diego, San Francisco, and Santa Clara) received a CPRA letter asking for all material related to Proposition 99 funded projects since January 1989 (hundreds of documents, an average of 3550 to 4000 pages per request per LLA), with a $\$ 50$ personal cheque enclosed. In most cases, the amount sent did not cover the costs of copying (at 25 cents a page), and an additional amount was sent. As previously mentioned, CDHS policy does not include charges for time spent in complying with CPRA requests. ${ }^{36}$ Although the letters were each signed by a different person, who lived in the county the LLA served, they followed a form letter format. The text of the letters was either the same (including typographical errors) or very similar, indicating an organised campaign to obtain documents from the LLAs.

The American Smokers' fournal, one of the several pro-tobacco industry publications, ${ }^{37}$ later reported that the CPRA letters to the LLAs were a "coordinated effort by members of Californians for Smokers' Rights" to investigate any misuse of public funds. ${ }^{38}$ None of the letters' authors, however, acknowledged being a member of CSR. Further, several of documents requested were for duplicates of the documents that CSR had already requested from TCS. In March 1992, the number of CPRA requests to LLAs prompted TCS to 
send a memorandum to all Tobacco Control Project directors outlining CDHS's policies to deal with CPRA requests and urging each county to contact their county counsel on following county procedures in dealing with such requests. ${ }^{39}$

CSR has also been monitoring local coalition meetings. Local coalitions of community members, initially organised by the LLAs, played a major independent role in the development of local tobacco control ordinances throughout California, contributing to reduced tobacco consumption. CSR called several LLAs (including Alameda, Contra Costa, Marin, Sacramento, San Francisco, San Mateo, Santa Clara, San Diego, and San Luis Obispo) to find out meeting dates. To date, only coalition meetings in Sacramento have been consistently attended by a CSR employee, Glenn Williams. Over time, coalition members learned to accept the fact of potential presence of pro-tobacco interests in their meetings, and they continue to carry on their business as usual, warning other coalitions and tobacco control professionals that they should not let this presence intimidate them or deter them from pursuing their planned activities. ${ }^{\mathbf{4 0 , 4 1}}$

San Francisco was also the focus of several other CPRA requests in Autumn 1993, when a smoke-free workplace ordinance was under active consideration. The requests came from the law firm Bagatelos and Fadem, both former lawyers at Nielsen, Merksamer et al. This law firm was also associated with Long Beach Business and Convention Coalition, Californians for Fair Business Policy, and the Los Angeles Hospitality Coalition, tobacco industry front groups involved in defeating local ordinances in California. ${ }^{8,15,29}$ In addition, Bagatelos is also associated with CALSTOP, a smokers' rights group associated with the Tobacco Institute. ${ }^{29}$ At the time, tobacco control staff had to divert time away from informing the public about the dangers of secondhand smoke and from responding to technical questions from the board of supervisors (the local legislative body) regarding the ordinance so that the demands for documents from the tobacco industry representatives could be met.

\section{ACTIVITIES AT THE FEDERAL LEVEL AND IN} OTHER STATES

The Office on Smoking and Health (OSH) of the Centers for Disease Control and Prevention (CDC) has consistently received FOIA based requests, mainly through law firms, ${ }^{42-47}$ document research, and retrieving companies, ${ }^{48-53}$ and, in at least one instance, from the Tobacco Institute itself. ${ }^{54}$ In general the requests are for drafts and all documents related to the surgeon general's reports on the health dangers of tobacco use, as well as for any other CDC sponsored activity such as conferences, meetings, media campaigns, special projects, and committees. In some instances, recommendation is made by OSH that predecisional documents or work in progress be exempt from release, although the decision ultimately rests with either CDC administration or the Public Health Service. OSH staff keep track of the time spent as well as the copying costs, and CDC usually recovers all or some of the costs incurred. The Office on Smoking and Health, which is part of CDC's National Center for Chronic Disease Prevention and Health Promotion, is the office that receives the most FOIA requests in this centre. From 1991 to May 1995, OSH received a total of 88 FOIA based requests (45 in the 1991-93 period, 26 in 1994, and 17 in 1995), and the number has been increasing steadily since 1993 (Sal Lucido, personal communication, June 1995).

In 1992 the tobacco industry filed an FOIA request with the National Cancer Institute (NCI) for all the documents related to the Community Intervention Trial for Smoking Cessation (COMMIT) programme, particularly the data tapes of COMMIT evaluation studies, and tapes and completed questionnaires of a COMMIT youth survey of 9th grade students. COMMIT was a controlled trial to assist heavy smokers to stop smoking through increasing the level and availability of community based smoking cessation resources. It was conducted in 11 community pairs, 10 in the USA and one in Canada. ${ }^{55}$ At that time, several documents and protocols were released, but the data tapes were withheld on the basis that it was predecisional information that could potentially change the outcome of the controlled trial. The case was taken to the United States district court for the District of Columbia (Civ No 92-2636-GHR) and is still under consideration.

Also in 1992, at the same time that TCS received the request for the data tapes from the UCSD survey linking RJR's Joe Camel character with children's smoking, NIH received a very large request for all documents related to research on tobacco advertising and youth smoking, as well as to CDC's 1989 Teenage Attitudes and Practices Survey (TAPS), which also had shown that cigarette advertising plays a role in causing tobacco use by children. ${ }^{56-58}$

Another NCI funded tobacco control programme, the American Stop Smoking Intervention Study for Cancer Prevention (ASSIST), has also received several FOIA requests from the Tobacco Institute as well as from other representatives of tobacco interests, including law firms, since its early stages in 1991. The requests were directed both at NCI and at some of the 17 states awarded contracts by NCI. For example, the departments of health in Colorado, Massachusetts, Minnesota, North Carolina, New Mexico, and Missouri have received several requests for documents related to the development of their programmes. How much information is released in particular states varies according to the language and scope of each state's public records act.

In Autumn 1994, the Colorado State Health Department received several requests for public records. The information obtained was later used in an attempt by the tobacco industry 
lobbyists to connect department staff with allegedly illegal participation in a campaign to pass Amendment 1, a proposition similar to California's Proposition 99. ${ }^{59}$ The tobacco industry defeated Amendment 1 at the ballot. The Colorado experience illustrates another possible intent of the public records requests by the tobacco industry, which is an attempt to connect public funds with allegedly improper lobbying activities by government employees. Thus it is extremely important that educational activities, including those aimed at educating the legislature and policy makers, be written in clear language so as not to be misconstrued or misrepresented by the tobacco industry.

Both at the federal level and in other states, the effects and the characteristics of the tobacco industry requests are similar to those observed in California. In one instance, NCI had to hire a separate person to process requests under FOIA; otherwise, the volume of requests and the amount of time to comply with them would have required staff time to be diverted from programme functions to retrieve and copy the material requested, impairing the ability of regular programme activities to take place.

\section{COMPARISON WITH NON-TOBACCO} PROGRAMMES

In the time studied, the Department of Health's AIDS programme did not receive any CPRA requests. In fact, in the past eight years, this programme has only received an estimated total of 10 requests for documents. The Department of Education's HIV prevention and education programme has never received a CPRA request. The alcohol and drug abuse programme of CDHS had no record on how many requests had been received, but the community relations officer stated they were rare.

The Air Resource Board (ARB) reported receiving an average of 100 requests per year, almost all from lawyers representing a variety of interests, since their regulatory scope is very broad. In contrast to the all-encompassing general requests received by TCS, however, the requests to the $A R B$ were generally narrowly specified, focused in limited areas related to a specific regulatory action by $A R B$, and did not include threats of legal action. When the request is too large, the ARB makes the documents available for inspection at its office so as not to disrupt its regular activities.

\section{Discussion}

The laws addressing the right to access to public records give taxpayers a legitimate tool to monitor spending of public money and government activities. However a quantitative and qualitative difference in information requests received by tobacco control programmes and other public health problems (such as AIDS, and Drugs and Alcohol) is evident, suggesting that the tobacco industry is using public records acts as another tactic in their strategy to disrupt public health efforts to control tobacco and to influence policy making in this area. In all but one instance the industry did not openly admit to being the requester of the information.

The tobacco industry's CPRA and FOIA requests create an environment where staff have to work under a high degree of scrutiny from an industry with unlimited legal resources. Further, the involvement of lawyers following up on requests and threats of lawsuits brought a legal focus to what would otherwise be a routine response to a public request. A structural evaluation of California's tobacco control programme conducted by the $\mathrm{CDC}^{7}$ found that "the demands of the tobacco industry on the staff of TCS for responding to requests for documents amount to a tax-payer subsidy of the industry as it tries to protect its interests at the expense of the health of California" (p 17).

The information obtained through the CPRA actions permits pro-tobacco groups to quote documents describing tobacco control projects out of context, and to focus on personnel and budget information to mislead the press and the public as to how Proposition 99 funds are used. As an example of the misinformation and distortion campaign, CSR issued a press release in April 1993 listing 10 projects that they ridiculed as wasteful of taxpayers' money. ${ }^{60,61}$ The 10 projects on the list were chosen out of approximately 450 projects funded through the LLAs or through the CDHS competitive grant system. The list includes such projects as participation in the University of California (Davis) picnic day parade; a workshop for youth in Kings County that included a pool party; a smoke-free baby shower in Solano County; exercise classes for smokers in Alpine County; a "Breathe easy, smoke-free" walk through Yosemite National Park, sponsored by Mariposa County; and the sponsorship of a racing car by the Bay Area Cancer Coalition. Although CSR focused on projects that appeared frivolous, these specific projects were positively evaluated by both participants and staff in getting the tobacco control message across, mainly to teenagers. ${ }^{40}$ Ironically, the strength of the response from pro-tobacco groups might serve to indicate the effectiveness of these Proposition 99 funded programmes. The CSR press release received wide coverage, and TCS and LLA staff had to dedicate several hours to respond to the release. ${ }^{62-65}$

Before being used in the press release, the information obtained by CPRA requests was also used in a brochure sent to voters in Massachusetts ${ }^{66}$ in Autumn 1992 as part of the tobacco industry campaign against Question 1 (Massachusetts' tobacco tax initiative, similar to Proposition 99). The brochure portrayed California's tobacco education efforts as "frivolous programs and bureaucratic waste." All the projects chosen in the brochure are mentioned in CSR's press release. Other industry campaign activities to defeat Question 1 also included several public records requests to the Massachusetts Health Department's Office for Nonsmoking and Health. Similar to California, the requests were for a wide range 
of unspecified documents. ${ }^{67}$ After passage of Question 1 the health department continued to receive requests for documents related to the Question 1 fund expenditures, and, as previously mentioned, as an ASSIST site Massachusetts had already been targeted by additional FOIA requests.

The tactics of using CPRA requests and launching a disinformation campaign are pieces of an strategy to discredit Proposition 99 funded projects, and is similar to other disinformation campaigns launched by the tobacco industry. ${ }^{68}$ This tactic, together with substantial campaign contributions to legislators, ${ }^{9}$ organising smokers' rights groups, ${ }^{14}$ and the use of front groups and law and public relation firms ${ }^{15}$ in California's local and state policy making have been combined into a successful strategy to seriously compromise the tobacco control programme. ${ }^{69}$

Most important, this information was being gathered in anticipation of the hearings for re-authorisation of Proposition 99 expenditures, held in $1994 .^{8}$ Even though the voters enacted Proposition 99 with specific allocations to tobacco control, the legislature must enact authorising and appropriating legislation to actually spend the money every few years. This authorising legislation has provided the tobacco industry with opportunities to persuade legislators to reduce the tobacco control funding below that mandated by the voters in Proposition 99. ${ }^{9}$ The information obtained through the CPRA was used in the 1994 debate over authorising legislation for Proposition 99, Assembly Bill 816 (AB 816, sponsored by assemblyman Phil Isenberg, DSacramento). A list with nine health education and eight research projects (not discussed here) was produced by assemblyman Isenberg's office $^{70}$ and distributed to legislators and the media during the hearings on the re-authorisation bill in a successful effort to discredit the tobacco research and health education programmes and to justify significant reductions in its funding.

In addition, there are signs that CPRA requests will also play a role in a potential tobacco industry attempt to weaken or eliminate California's Assembly Bill 13 (AB 13). AB 13, which became effective on 1 January 1995, mandated statewide restrictions on workplace smoking, with some exemptions, but left implementation and enforcement to local government units. As of summer 1995, several counties had received CPRA based requests for all materials related to the implementation and enforcement of AB $13 .{ }^{71-75} \mathrm{It}$ is not clear at present how the tobacco industry will use this information.

\section{AN APPROPRIATE RESPONSE}

As the tobacco industry's campaign to access documents related to tobacco control strategies intensifies, public health agencies need to develop a mechanism to systematically document and exchange information about these requests and the requesters, as well as to make sure all those involved are aware of depart- mental policies to deal with such requests. The TCS and LLAs attempt to respond to these requests with minimal disruption of their activities by asking that requests be in writing, carefully documenting all CPRA related matters, and not allowing this campaign to halt their efforts to promote a healthier environment.

One approach to deal with pro-tobacco CPRA requests such as these is to expose the request to the public, making use of the media, as exemplified by the events in Contra Costa County. The CPRA letter to the Contra Costa County tobacco control project (TCP) was signed by Marietta Stuart. The TCP director answered that to comply with the request would take too much staff time and it would be disruptive to the LLA's work. She suggested scheduling a time for Ms. Stuart to come in and use the copy machine and to inspect the documents. ${ }^{76}$ In response, TCP received a call from the law firm Bell and Hiltachk, representing CSR, stating that they would send someone with a copy machine to photocopy the documents. When Glenn Williams, CSR employee, arrived at TCP with a copier, the TCP director was waiting with the media to denounce what she perceived as harassment by pro-tobacco groups. The American Smokers' fournal covered the event, stating that Glenn Williams was "simply looking for answers," without mentioning that Williams was a CSR employee. ${ }^{38}$ The incident received wide coverage in the press and requests to the LLA stopped. ${ }^{72-80}$

Another important approach is to continue with efforts such as the information exchange conference that took place in San Francisco in May 1994 sponsored by ASSIST, the American Cancer Society, and the California Department of Health Services. At the Conference, LLA and ASSIST staff had the opportunity to exchange information and strategies to promote tobacco control and counteract the tobacco industry attempts to hinder public health efforts.

Finally, state and federal level agencies should make an effort to recover some of the costs associated with responding to these large requests, including copying expenses and employee time. When permitted by the Public Records law, time spent should be recorded so the state can be reimbursed. Even where reimbursement for time is not allowed, as in California, it would be useful to have a record of how much the tobacco industry's public records requests are costing taxpayers.

\section{LIMITATIONS}

Since this is an observational rather than an experimental study, the data used in this study do not allow for definite causal relationships to be established. The only records available were the CPRA files at TCS, which included requests and some of the responses provided by TCS to requesters. There is a possibility of underestimating the ramifications of the large increase of CPRA requests directed to TCS, and how they affected its activities. While a
$=$

$+$

$=-$

2

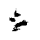

;

$\neq$

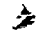

$>$

2

$\div$ 

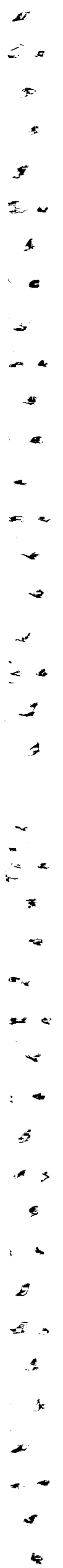

substantial amount of time was spent both in answering the requests and on internal meetings, there is no precise record of this time. The influences of the information obtained from the CPRA campaign on authorising legislation is inferential, but agreed upon by all of those interviewed.

There may be several other instances where public records acts were used by the tobacco industry interests at the federal, state, and local levels. However, an analysis of all such requests to all government agencies was beyond the scope of this study.

Further research in this area is needed, with more controlled methodology and data collection methods. As public health professionals become aware of the use of the freedom of information laws as a disruption strategy, such requests should be carefully documented to clarify the links between the requests and attempts to interfere with tobacco control programs.

\section{CONCLUSIONS}

This systematic disruption of tobacco control programmes through the use of public records acts is not exclusive to California. The apparent increase in FOIA related activities in other states and at the federal level resembles an organised campaign, rather than an isolated California phenomenon, suggesting that the tobacco industry is using public records acts as another tactic in its strategy to derail public health efforts to control tobacco use.

Public health professionals working on tobacco control, both in policy and health education arenas, should anticipate such requests. They must be prepared to answer them with careful attention to the law. They should be briefed in the proper handling of freedom of information act requests. High level administrative and legal offices within the health department (or other relevant agency) should be prepared to respond to tobacco industry requests, while protecting the integrity of government programmes and employees. Summary reports and other public documents should be used when possible to defer non-specific requests for "all" documents. Public health authorities must be prepared to respond to public relations campaigns based on out-of-context representations of the material obtained through these requests. Public records requests are often so extreme that complying with them can be made a media event, which may discourage tobacco interests from further use of this tactic. As more and more states attempt to deal with the epidemic of tobacco induced diseases, we anticipate that efforts by the tobacco industry to use state and federal freedom of information acts to disrupt this activity will intensify.

Access to public records is every citizen's right. Unfortunately, it appears that the tobacco industry is abusing this right and turning it into a weapon to complicate and discourage public health activities.

This work was supported by the Cigarette and Tobacco Surtax
Fund of the State of California through the tobacco-related disease research program of the University of California Awards 1RT520 and 3KT0349, and National Cancer Institute research grant CA-61021. We thank Thomas Novotny and Michael Begay for comments on drafts of this manuscript.

1 United States. 5 United States Code Sec 552.

2 US Department of Health and Human Services Ethics Advisory Board. The request of the Center for Disease Control for a limited exemption from the Freedom of Information Act. Department of Health and Human Services, 1980.

3 California Annual Government Code, Public Records Act Secs 6250 et seq.

4 Office of Information Practices. The Information Practices Act of 1977 with guidelines and commentary, 6th ed. Sacramento, CA: State Personnel Board, 1986.

5 Bal DG, Kizer KW, Felten PG, Mozer MH, Niemeyer D. Reducing tobacco consumption in California: development of a statewide anti-tobacco campaign. $\mathscr{f} A M A$ 1990; 264: 1570-4.

6 Pierce JP, Evans N, Farkas AJ, et al. Tobacco use in California: an evaluation of the tobacco control program California: an evaluation of the tobacco control program, Health Services. San Diego: Cancer Prevention and Control Program, University of California at San Diego, 1994.

7 US Centers for Disease Control and Prevention. Structural evaluation, California's Proposition 99-funded tobacco control program. Rockville, Maryland: Public Health Service, Centers for Disease Control and Prevention, 1994.

8 Begay ME, Traynor MP, Glantz SA. The twilight of Proposition 99: reauthorization of tobacco education programs and tobacco industry political expenditures in 1993. San Francisco: Institute for Health Policy Studies, University of California at Sar

9 Begay ME, Traynor MP, Glantz SA. The tobacco industry, state politics, and tobacco education in California. $A m \mathcal{F}$ Public Health 1993; 83 : 1214-21.

10 California Wellness Foundation. California strategic summit on the future of tobacco control. California Wellness Foundation, 1993.

11 California Smoke-Free Cities Bulletin. Sacramento, California: 1994; issue 4

12 Californians for Smokers' Rights. The CSR Report, autumn 1991.

13 Californians for Smokers' Rights. Letter sent to CSR members, 1992.

14 Samuels B, Glantz SA. The politics of local tobacco control. 7AMA 1991; 266: 2110-7.

15 Traynor MP, Begay ME, Glantz SA. The new tobacco industry strategy to prevent local tobacco control. $\mathcal{f} A M A$ industry strategy to

16 Lundgren E. Letter sent to Rf Reynolds mailing list, 1994.

17 Shapiro E, Wartzman R. Tobacco lobby finds its influence waning as health issue grows. Wall Street fournal, 24 March 1994: A1, A5.

18 Flesher D. A match made in heaven? York Daily Record, 2 January 1994.

19 Tobacco Education Oversight Committee. Toward a tobacco-free California: exploring $a$ new frontier 1993-1995. Sacramento, CA: TEOC, 1993.

20 Tobacco Education Oversight Committee. Toward a tobacco-free California: a master plan to reduce Californians' use of tobacco. Sacramento, CA: TEOC, Caliform 1991 .

21 California Department of Health Services and California Department of Education. Toward a tobacco-free California: a status report to the California legislature on the first fifteen months of California's tobacco control the first fifteen months of California's tobacco control
program. Sacramento, CA: CDHS and CDE, 1990.

22 California Department of Health Services and California Department of Education. Toward a tobacco-free California: $a$ report on the activities and evaluation of California's tobacco control program. CDHS and CDE 1992.

23 Los Angeles Hospitality Coalition. Campaign disclosure statement - long form. California Secretary of State Political Reform Division, 1994

24 Aguinaga S, Macdonald HR, Traynor M, Begay M, Glantz SA. Undermining popular government: tobacco industry political expenditures in California, 1993-1994. San Francisco: Institute for Health Policy Studies, University Francisco: Institute for Health Policy

25 Escher HJ. Letter to Bill Ruppert. Sacramento, CA CDHS/TCS, 1992.

26 Pierce JP, Gilpin E, Burns DM, et al. Does tobacco advertising target young people to start smoking? Evidence from California. $\mathcal{F} A M A 1991 ; 266$ : 3154-8.

27 Gard B. Letter to San Carlos City Council Member Paul Sivley, 1993.

28 Knepprath P. Memo to Rowland Company. American Lung Association, Sacramento: 1993.

29 Tobacco industry front groups. Berkeley, CA: Americans for Nonsmokers' Rights, 1993.

30 The Claremont Institute. Financial statement, 1993. California: California Registry of Charitable Trusts, California: California Registry of Charitable Trusts, 31 Merrell 1992.

32 Ryan JA. Letter to Dennis Eckhart, supervising deputy attorney general. Sacramento, CA, 1995.

$$
\text { . }
$$

$$
\text { N }
$$$$
\text { T }
$$ 
33 Niemeyer D. Letter to Mark Helm, law office of Munger, Tolles and Olsen Sacramento, California, 1991.

34 Nelson J. Letter to Tobacco Control Section of the California Department of Health Services. California, 1993.

35 Shimizu R. Letter to fohn Nelson. Sacramento, CA: Tobacco Control Section, California Department of Health Services, 1993.

36 California Department of Health Services. Department administrative manual. Public access to departmental records. Sacramento, CA: California Department of Health Services, 1990: ADM 90-1.

37 Cardador M, Hazan AR, Glantz, SA. Tobacco industry smokers' rights publications: a content analysis. $A m \mathcal{F}$ Public Health 1995; 85: 1212-7.

38 United Smokers Association of America Publication. Krazy Kalifornia. American Smokers' fournal, 2nd Quarter 1993: 7.

39 Tobacco Control Section, California Department of Health Services. Memorandum. Sacramento, California, 1993.

40 Interview with Carol Russell. Tobacco Control Section, California Department of Health Service, 1993.

41 Interview with Paul Knepprath and Betty Turner. American Lung Association, Sacramento, California, 1993.

42 Sidak ML. Covington \& Burling letter to $L$ Leathers, FOIA coordinator at the Office of Public Affairs, Centers for Disease Control. Washington, DC, 1990

43 Rupp JP. Covington \& Burling letter to D Christian, freedom of information officer at the Office of Smoking and Health, Centers for Disease Control. Washington, DC, 1988 .

44 Rupp JP. Covington \& Burling letter to R Roberts, director of freedom of information division, US Department of Health and Human Services. Washington, DC, 1986.

45 Kahan JS. Hogan \& Hartson letter to freedom of information officer at US Public Health Service. Washington, DC, 1987

46 Cilman AJ. Alan J Cilman FOIA Request letter to US Department of Health and Human Services Francisco, California, 1989

47 Stuhan RG. Jones, Day, Reavis \& Pogue letter to D Berreth at the Freedom of Information Office of the Centers for Disease Control. Cleveland, Ohio, 1987.

48 Eisemann D. Federal document retrieval letter to D Berreth, freedom of information specialist at the Centers Berreth, freedom of information specialist at

49 Nuss A. Federal document retrieval letter to D Christian, freedom of information specialist at the US Public Health Service. Washington, DC, 1989.

50 Nuss A. Federal Document Retrieval letter to D. Christian, freedom of information specialist at the the US Public Health Service. Washington, DC, 1988

51 O'Brien SB. Washington Service Bureau letter to $R$ Roberts, freedom of information officer at the US Department of Health and Human Services. Washington,
DC, 1988.

52 Rusby PB. The SRC Group Inc letter to D Berreth at the Centers for Disease Control. Washington, DC, 1987.

53 Small PS. FOI Services Incorporated letter to the Office on Smoking and Health. Rockville, Maryland, 1989.

54 Duppin AH. The Tobacco Institute letter to D Berreth, freedom of information specialist at the Centers for Disease Control. Washington, DC, 1988.
55 The COMMIT Research Group. Community intervention trial for smoking cessation. I. Cohort results from a four-year community intervention. Am f Public Health $1995 ; 85$ : 183-91.

56 Fischer PM, Schwartz MP, Richards JW, Goldstein AO, Rojas TH. Brand logo recognition by children aged 3 to 6 years old. $\mathcal{F} A M A$ 1991; $266: 3145-8$.

57 DiFranza JR, Richards JW, Paulman PM, et al. RJR Nabisco's cartoon camel promotes Camel cigarettes to children. $\mathcal{J} A M A 1991 ; 266: 3149-53$.

58 Burka R. Letter to NHI freedom of information officer Washington, DC, 1992

59 Lipeher S. 4th complaint filed against tobacco tax. The Denver Post, September 16, 1994.

60 Californians for Smokers' Rights. Press release. California, 1993.

61 Californians for Smokers' Rights. The CSR report. California, summer 1993

62 Smokers fume at use of tax funds. San Bernardino Sun, April 23, 1993

63 Smokers' group fumes over use of tobacco tax funds. Santa Cruz Sentinel, April 23, 1993.

64 Bancroft A. Smoking advocates fuming over tax use. San Francisco Chronicle, April 23, 1993.

65 Monroe R. Smokers' group fuming over Kings' pool party. Hanford Sentinel, April 26, 1993.

66 Committee Against Unfair Taxes. Mailing to voters in Massachusetts. Massachusetts, 1992

67 Philips F. Tobacco industry seeks Health Dept files. Boston Globe, October 3, 1992: 16

68 Secondhand smoke: is it a hazard? Consumer Reports 1995: 27-33.

69 Tobacco tax's future is in court hands. San Francisco Daily Fournal, July 18, 1994: 1,6.

70 Assemblyman Phillip Isenberg's Office. Some tobacco tax local anti-tobacco "health education" and some tobacco tax "disease" research funded by UC. Sacramento, California, 1994.

71 Archibald DF. Barnes \& Associates Professional Services Inc letter to Imperial County Health Department. Los Angeles, California, 1995.

72 Archibald DF. Barnes \& Associates Professional Services Inc letter to Calaveras County Health Department. Los Angeles, California, 1995.

73 Archibald DF. Barnes \& Associates Professional Services Inc letter to Butte County Health Department. Los Angeles, California, 1995

74 Archibald DF. Barnes \& Associates Professional Services Inc letter to Santa Barbara County tobacco prevention program. Los Angeles, California: 1995.

75 Zeiler KP. Barnes \& Associates Professional Services Inc letter to Vallejo City. Los Angeles, California, 1995.

76 Ellis G. Letter to Marietta Stuart. Pleasant Hill, California: Tobacco Prevention Project, 1993.

77 Smokers' Rights Ambush. Richmond Post, April 21, 1993. Sparks fly between pro and anti-smokers' groups. The Valley Times, April 14, 1993.

79 Gaura M. No-smoke educators link foes to industry. Contra Costa Times, April 13, 1993.

80 Lewis C. Anti-smokers stage challenge. Oakland Tribune, April 14, 1993. 